Naomi Boakye

\title{
The social dimension of reading literacy development in South Africa: Bridging inequalities among the various language groups
}

DOI 10.1515/ijsl-2015-0008

\begin{abstract}
It is widely acknowledged that different communities, such as language groups and socio-economic status (SES) families, practice literacy in different ways. Certain language communities of low SES observe literacy interactions differently from the traditional "schooled literacy", which may influence learners' reading literacy. However, the link between language communities, SES and reading literacy has not been extensively researched, especially in the South African context where there are 11 official languages and wide socio-economic disparities. This article examines students' social literacy in relation to their reading literacy levels, and reveals that the literacy gap between indigenous South African language (ISAL) speakers, a number of whom are from low SES families, and speakers of English and Afrikaans is further widened at the tertiary level due to the mismatch between the social literacy practices of the different language groups and the education system that operates in the country. Recommendations are made on how educators could employ strategies such as social relevance and culturally sensitive teaching to bridge the academic literacy gap among the language groups.
\end{abstract}

Keywords: reading literacy, social literacy, social relevance, academic literacy, language groups/communities

\section{Introduction}

Reading is perceived by most reading researchers as a cognitive, affective and social activity (Bus 2001; Grabe and Stoller 2002; Guthrie and Wigfield 2000; Verhoeven and Snow 2001). Although it has been primarily construed as a cognitive-linguistic accomplishment by cognitive linguists (e.g. Goodman 
1976), it is also a socially constructed phenomenon. It is a form of human behaviour and a social practice, as argued by socio-cultural theorists such as Gee (2008) and Street (2003). Traditionally perceived as a cognitive ability rooted in the autonomous view of literacy, reading literacy is currently viewed by many researchers as a social practice due to the emergence of the New Literacy Studies (NLS) that brought a socio-cultural dimension to the understanding of the concept. Verhoeven and Snow (2001) propose a redefining of literacy to acknowledge the degree to which it is a social activity and an affective commitment in addition to being a cognitive development. Alderson (2000: 25) refers to Hill and Parry's (1992) Pragmatic Model of literacy and explains that reading is "context-bound and socially embedded". The plurality of literacies is also included in this concept as the new understanding of literacy goes beyond the traditional cognitive view of literacy to include literacy in various contexts such as the home and language communities. The concept of social literacies includes the social beliefs, values and conventions that define literacy practices in particular contexts (Street 1997).

The importance of this form of literacy in relation to academic reading literacy and academic performance has been widely considered (Heath 2001; Gee 2008; Street 1997). However, the implication of various social literacies in relation to the classroom has not been adequately researched. Classroom social literacies and social disparities are evident in former colonial and multilingual countries such as South Africa, which has adopted 11 official languages. The article investigates social literacy in relation to language groups and academic reading literacy levels of a cohort of first-year students in a South African university. I argue that the two groups of students (speakers of indigenous African languages, and mother tongue (MT) speakers of English and Afrikaans) from different cultural groups practise different social literacies with unequal power relations in their academic reading and learning endeavours. In the sections that follow, I discuss social literacy within the NLS, then characterise the South African context and present the study. Finally, I provide recommendations for the acknowledgement of alternative literacies that include social relevance in reading instruction.

\section{Social dimension of reading and the NLS}

Various research studies have shown that different communities practice literacy in different ways (Heath 1983; 2001; Prinsloo 2005; Street 1984 and Street 2001). Alderson (2000: 25), expounding on the cultural differences on literacy, states that the way literacy is valued, used and displayed varies from culture to culture. 
Some cultures have enormous respect for the printed word to the extent that it is implicitly accepted as authority and cannot be questioned. Others fear the implications of putting their opinions in print, due to more accountability. Heath (1983, 2001) documents research on socio-economic status (SES) and language communities and shows how the use of literacy in homes is different for different language communities and different SES families. She showed how these different literacy practices affected learning in school. She found in her study that the black working class (low SES) community were less focussed on written texts, but more skilled in oral storytelling. Creative analogy, rich storytelling and metaphors were essential to this community. The white community of similar SES in the study were religious and placed more emphasis on written scriptures. The white middle-class community engaged in bedtime stories and talked explicitly about texts. She concludes that there are greater differences between schooled literacy practices and the ways that literacy was enacted in the lower SES communities as well as between schooled literacy practices and those of the white middle-class community.

Whereas the traditional view of literacy was cognitive oriented, and explained literacy as a set of abilities or skills residing inside people's heads, the NLS viewed literacy from a socio-cultural perspective. The NLS proponents argue that greater emphasis should be placed on taking account of the variety of literacy practices that exist in homes and communities and that these should be valued rather than ignored. Street (1997, 2001) and Gee (1991), among others, propose that literacy practices in which learners are engaging in everyday life must be considered as potential resources for meaning making in formal educational contexts. A social perspective on literacy does not focus on individual acquisition or use of skills, but rather on the ways people use written language in their everyday lives. According to Barton and Hamilton (1998) literacy is conceptualised primarily as a social activity and best understood as a set of social practices, patterned by social institutions and power relationships, and that some literacies are more dominant, visible and influential than others. The academic community operates mainly on a dominant, cognitive-oriented concept of literacy. The NLS (e.g. Gee 2008; Street 2001) has challenged the solely cognitive perspective of literacy education and argues for alternative approaches to literacy and learning. According to Gee (2008: 2) literacy entails the full range of cognitive, social, cultural, political, institutional, moral and historical contexts.

Cognitive linguists focus on the traditional, cognitive aspects of reading to determine and enhance reading literacy. NLS proponents (e.g. Gee 2008; Street 2001) on the other hand, believe in integrating the socio-cultural aspects that perceive reading as a social practise that involves literacy practices in various contexts. Serpell (2001), Street (2001) and others acknowledge the influence of social factors in reading development, and argue for socio-cultural underpinnings 
to literacy development. Street (1997: 79) refers to the social dimension of reading as social literacies. He states that social literacies "refer to the nature of literacy as social practice and to the plurality of literacies that it enables us to observe... [L] literacy is always practiced in social contexts and that even the school... is also a social construction”. Social literacy could be defined as learners' reading and writing experiences at home and in the community. It also involves the literacy interactions between family members, friends and the society as a whole. Alderson (2000) argues that social factors, such as the literacy interactions among family members and friends, influence a student's ability to read proficiently. This type of literacy starts right from the crib when parents read to their children, and continues to develop as they are taken to libraries to read, and as discussions are made around texts. Research has shown that as children are read to they develop basic prereading skills and sentence structure awareness (Greaney 1996; Pretorius 2007). Heath $(1983,2001)$ and Freebody et al. (1995) point out that in a print-rich home environment, reading among family members and the discussions of texts are all forms of social literacy that may develop and enhance reading proficiency.

The relationship between social literacy on the one hand and reading literacy and academic achievement on the other, has been a subject of debate internationally. Freebody et al. (1995) report about research in Australia that explored the complexity of social literacy in different contexts, focussing on class and SES. The team of researchers studied literacy practices of low SES urban communities in the home and in school and challenged the dominant representation of literacy in schools. They recommend that effective pedagogy of literacy instruction should involve literacy that is mutual (i.e. from the school and home perspectives). Bus (2001) highlights the social aspect of reading development strongly in his study. He shows from his study that the interactive experience that children receive from their parents affects the frequency and quality of parent-child book reading and, consequently, the development of literacy. Grabe and Stoller (2002) concede that:

This emphasis on individual processes is not intended to deny the relevance of social factors on reading development (e.g. family literacy experiences... and peer and sibling interaction around literacy events) or the relevance of social contexts on purpose and processes themselves....(Grabe and Stoller 2002: 31)

There is no doubt that social issues are considered as relevant in students' reading development. However this has not been transferred to practical teaching. Verhoeven and Snow (2001: 11) state that procedures for incorporating this acknowledgement into actual teaching practice are not widely implemented. Greaney (1996) and Elley (1996) lament that many teachers especially in developing countries still focus solely on skills in reading instruction. A number of 
reading intervention programmes, both nationally and internationally, focus mainly on skills and explicitly teach reading strategies, critical reading, vocabulary, and other aspects of reading, purely from a cognitive-oriented perspective.

In addition, research shows that he home environment exerts a great influence on learners' reading literacy (Greaney 1996). Children from homes that are print-poor (that is, with few or no books) do not usually acquire the habit of reading before starting school and tend not to find reading pleasurable (Pretorius 2007). Consequently, at tertiary level they find reading burdensome. An International Association for the Evaluation of Educational Achievement (IEA) study identified the home environment as the single most critical factor in the development of literacy (Greaney 1996: 13). Having parents, siblings and significant adults who do not engage in reading or do so sparingly, strongly influences the importance that students attach to reading. Both conditions are usually the result of poverty (Currin and Pretorius 2010).

\section{The South African context}

After South Africa gained independence in 1994 the language policy was extended to include all the indigenous South African languages (ISAL). Although this meant that the country had 11 official languages (English, Afrikaans and nine ISAL), the language of instruction has been mainly English. A few schools do have Afrikaans as the language of instruction, and at the tertiary level some institutions give students the choice to study in English or Afrikaans. However, ISAL speakers do not have this option. Even from Grades R-3 where instruction is officially to take place in the home language (HL), a number of schools use English for various reasons (de Klerk 2002; Jansen 2013). In schools where ISAL MT instruction is undertaken at the foundation level, various factors such as limited access to reading materials, poor resources and inappropriate teaching methods militate against effective instruction. When the switch is made from MT instruction to English, the language of learning and teaching (LoLT) at Grade 4, learners are already disadvantaged as they have not received a solid schooled literacy foundation in either English (LoLT) or their HL.

In addition to being disadvantaged at school, the ISAL students may also have experienced literacy interactions that are not congruent with the school literacy practices. This mismatch between home and school literacies may negatively affect students' learning and reading practices (Niven 2005; Taylor and Yu 2009). 
According to Taylor and Yu (2009: 67) the "bimodal” education system in South Africa, which "refers to the phenomenon where two separate distributions corresponding to two differently functioning parts of the school system are concealed within the overall distribution of achievement", plays a pivotal role in disadvantaging black ISAL students. In other words, the two systems of school education functioning differently from each other exist under one education department (Fleisch 2008; Taylor and Yu 2009; Van der Berg 2008) and may be contributing to the low reading proficiency and academic performance of ISAL students. One "sub-system" consisting of approximately 80-85 per cent of South African learners is described as historically disadvantaged and most are currently poorly functioning (Taylor and Yu 2009). Learners in this "sub-system" of education are largely black, and the majority speak one of the ISAL as HL. Many of these learners are from a low socio-economic background and may have had minimal literacy interactions both at home and at school. In addition their literacy interactions as observed by Niven (2005) differ from the schools' literacy practices.

The other "sub-system" consists mainly of historically white and Indian schools and demonstrates much greater functionality (Taylor and Yu 2009). Learners in these schools are largely white and Indian and are from middle SES families. After independence in 1994, open access saw a number of blacks migrate to the historically white schools. These black ISAL HL speakers are mostly from middle-class families and most of them may have social literacy interactions that are compatible with the schools' literacy practices. They also have easy access to print materials due to their SES and the schools attended. The distinction is therefore between ISAL students, from low SES families, who attend poorly functioning schools on the one hand, and on the other, English and Afrikaans HL speakers, from middle SES families who attend better functioning schools. These two groups of learners from the different school subsystems converge at university and are taught and assessed on the same level.

\section{Social literacy and the language groups in South Africa}

Students whose SES and language group have led them to experience literacy interactions that are compatible with school literacy, have had early interactions with text and have attended better functioning schools as a result of their SES. Those with different forms of social literacy, for example, a strong emphasis on oral literacy traditions, have unfortunately not had frequent interactions with 
written texts (Niven 2005), and have attended poorly functioning schools (Pretorius 2000; Taylor and Yu 2009).

South Africa's bimodal school system relegates ISAL speakers to the historically disadvantaged and currently dysfunctional schools, whereas English and Afrikaans students are concentrated in the historically white and Indian schools that demonstrate much greater functionality. In addition, as demonstrated by Taylor and Yu (2009) through the PIRLS (progress in international reading literacy study) results, learners who performed poorly in the test were mostly from the historically disadvantaged schools and were ISAL speakers. Furthermore, these students were from low SES families. Taylor and Yu (2009) argue that learners' SES influenced their reading proficiency in direct and indirect ways. Direct influence emanates from the home support (e.g. social literacy), and the indirect influence stems from the school they attend as a result of their SES. In addition, the bimodal system of education, in which two separate distributions in literacy performance correspond to two differently functioning parts of the school system, has created a concentration of poor learners in poorly performing schools. According to Taylor and $\mathrm{Yu}$ (2009: 67), this further aggravates students' reading challenges, as studies have shown that a socio-economic mix of peers is an important school resource for achievement. When students are from different SES, they learn the school practices from each other, but when low SES learners are concentrated in a school, this aspect of learning is denied them.

A number of researchers (e.g. Makalela 2012; Pretorius 2007 and Pretorius 2008; Taylor and Yu 2009) have studied the reading challenges of South African learners in relation to SES but mostly with pre-tertiary learners. At the tertiary level, such research is limited. I present two such studies that relate to the sociocultural theory of Street (1997, 2003), Gee (2008) and others.

Napier and Makura (2013) investigated students' and lecturers' perceptions of an English language literacy support programme for students and found a mismatch between the students' (all ISAL HL speakers) perceptions of their English language literacy levels and that of their lecturers. The data showed that the students were far from developing academic literacies, had challenges in expressing themselves, grappled with skill acquisition more than developing an academic identity. Napier and Makura (2013) also found that while students did not perceive themselves as weak, they felt they needed English language literacy support. The researchers point out that the mismatch and the paradox presented in the responses "seem to suggest that linguistic barriers stem from students' background and academic contexts” (Napier and Makura 2013: 7). They recommend that lecturers should impart academic literacies to students through academic socialisation. In particular, they advocate that lecturers should be compelled to infuse academic writing in their assessment and 
learning regime, and that the academic literacies approach advocated by Lea and Street (2001) should be used to socialise students in academic writing.

Niven (2005) investigated the reading practices of 14 Foundation Year students at a South African university. These students were all ISAL from poor SES and attend rural schools that are under-resourced. Teaching in those schools is also less than the best as inappropriate methods are used, and library facilities are poor or non-existent. Niven concludes from her exploration that the difficulties students have in obtaining epistemological access were due to conflict of frames between their ways of knowing from literacy practices at home, and that of their lecturers' expectations. She argues that whereas the students brought a history of oral tradition of shared cooperative reading and learning in public places, the academic environment valued individualism and independent views. The mismatch between socio-cultural frames of the students and that of their lecturers caused them to be "anxious, withdrawn and passive, with very low levels of participation” (Niven 2005: 183). She warns, as does Boughey (2009), that without understanding the socio-cultural frames or the social literacy of those students the system will continue to produce education where the middleclass community will be the ones who benefit. Consequently, social injustice will continue to prevail in South Africa.

Although students' reading challenges have been studied and investigated, the relationship between language groups, SES and reading literacy of tertiary students in relation to social literacy in particular has not been researched. Given the 11 official languages and the socio-economic inequalities in the country, this omission is very glaring. The study aims to explore the relationship between students' social literacy, reading literacy and language groups.

\section{The study}

This study used a survey questionnaire to investigate the relationship between social literacy and reading literacy. The question that guided the study was: Is there a relationship between first-year university students' social literacy, language group and their reading literacy?

\subsection{Participants}

Two groups of first-year students participated in the study. One group consisted of first-year students taking the compulsory Academic Literacy (AL) module. 
These students had been identified by the reliable Test for Academic Literacy Levels (TALL) (Weideman 2011) to be at extremely high risk or at high risk of failure, academically. The total number of students who responded to the questionnaire from this group (High Risk) was 1,168.

The other group also consisted of first-year students who were registered for an elective module, Academic Reading, to fulfil the language requirement for their faculties. This group, referred to as the Low Risk group, were identified by the TALL as having low or negligible risk of failure. The total number of respondents from this group (Low Risk) was 1,107. The combined total number of respondents (High Risk and Low Risk) was therefore 2,258. Students in the High Risk group were predominantly ISAL HL speakers and those in the Low Risk group were predominantly English and Afrikaans HL speakers. The Other group consisted of all language groups outside South Africa. These were mostly from other African countries except for a few students from Asian and European countries. The distribution is given in Table 1.

Table 1: Literacy groups and HL of students.

\begin{tabular}{lrr}
\hline Home language & & Literacy levels \\
\cline { 2 - 3 } & $\begin{array}{r}\text { Extremely High } \\
\text { Risk and High Risk }\end{array}$ & $\begin{array}{r}\text { Low Risk and } \\
\text { Negligible Risk }\end{array}$ \\
\hline English & $7 \%$ & $42 \%$ \\
Afrikaans & $15 \%$ & $36 \%$ \\
ISAL & $65 \%$ & $15 \%$ \\
Other & $13 \%$ & $7 \%$ \\
\hline
\end{tabular}

\subsection{Instrument}

A questionnaire that consisted of a 5-point Likert scale (positive to negative) (see Appendix) was used to elicit students' responses. The questionnaire was divided into the categories of literacy interactions, reading experience (home and school) and reading habits. These categories formed part of a comprehensive questionnaire of nine categories that were used to investigate various aspects of students' reading. The three categories were used as independent variables in relation to students' literacy levels and language groups, which were the dependent variables. Students' reading proficiency or reading literacy levels were determined by the TALL. 


\subsubsection{Reading experience}

Questions for this factor probed respondents' past experience with reading in the home, at school and on a personal level. It was expected that a positive past experience with reading would lead to a love for reading, which leads to frequent reading, that results in the development of reading literacy (Grabe and Stoller 2002). A negative reading experience does not develop a love for reading and therefore reading is burdensome and rarely undertaken, leading to low reading proficiency levels (Grabe and Stoller 2002; Pretorius 2000). Reading experience would also shed light on students' literacy interactions at home and in school.

\subsubsection{Social literacy interactions}

Questions pertaining to this factor elicited students' reading in the social context, with family members, friends and the wider community. It is expected that students who interact in social environments that have high positive literacy practices will be influenced to read, and thus become proficient readers (Grabe and Stoller 2002). On the other hand, students who are raised in social environments with minimal or different literacy practices may not develop a love for reading and may not engage in frequent reading that develops reading proficiency (Grabe and Stoller 2002; Guthrie and Wigfield 2000; Pretorius 2008).

\subsubsection{Reading habits}

Questions relating to this factor tapped into the frequency with which students read, at the time of filling in the questionnaire, and the type of genres that they read; whereas questions on reading experience refer to past experience with reading from childhood, reading habits refer to current reading behaviour. Research has shown that positive reading habits develop reading proficiency (Grabe and Stoller 2002). It is expected that students who have positive reading habits will be proficient readers, whereas those with negative reading habits will be poor readers.

Students' reading experience, literacy interactions and reading habits may also be influenced by their socio-cultural practices as a result of SES and language groups (Alderson 2000; Grabe and Stoller 2002; Heath 2001). Those from middle SES families would have better reading literacy levels than those from low SES families. 


\subsection{Procedure}

The two groups of students, Low Risk and High Risk, completed the questionnaire at the end of the first semester. The High Risk group answered the questionnaire during one class period and the Low Risk group completed the questionnaire at the end of their first semester exam. Ethical issues were adhered to, as students read and signed the consent form for the use of questionnaire responses and TALL results. The TALL was written at the beginning of the first semester before the start of formal lectures.

\subsection{Data analysis}

The responses to the questionnaire and the results of the TALL were analysed by ANOVA test to determine the relationship between the students' social literacy, language groups and reading literacy levels. ANOVA tests are used to determine the relationship between different factors (variables).

\section{Findings}

The responses of the students showed a clear distinction of language groups and consequently, SES.

\subsection{Reading experience}

ISAL students responded negatively to statements on reading experience. The majority of the English and Afrikaans and a few middle-class ISAL HL speakers responded more positively. For example, statements such as "When I was a child I was often taken to the library" and "Members of my family used to read to me" (see Appendix for questionnaire) elicited high agreement (65\%) from the Low Risk group (predominantly English and Afrikaans HL speakers) and high disagreement (63\%) from the High Risk group (predominantly ISAL HL students). In other words, whereas the majority of the High Risk students were not taken to the library as children, the majority of the Low Risk students were taken to the library by their parents. The percentages of each group that agreed or disagreed with the statements are given in Tables 2 and 3, respectively.

The high percentages show agreement of the Low Risk group to the two statements (65\% and 75\%), as shown in Tables 2 and 3. It is evident that a majority of the Afrikaans and English HL students have had relatively better 
Table 2: Question - When I was a child I was often taken to the library.

\begin{tabular}{lrrrrr}
\hline $\begin{array}{l}\text { Literacy group (predominant } \\
\text { language group) }\end{array}$ & $\begin{array}{r}\text { Strongly } \\
\text { agree }\end{array}$ & Agree & Uncertain & Disagree & $\begin{array}{r}\text { Strongly } \\
\text { disagree }\end{array}$ \\
\hline High Risk (predominantly ISAL) & $9 \%$ & $18 \%$ & $10 \%$ & $23 \%$ & $40 \%$ \\
Low Risk (predominantly English & $27 \%$ & $38 \%$ & $4 \%$ & $21 \%$ & $10 \%$ \\
$\quad$ and Afrikaans) & & & & & \\
\hline
\end{tabular}

Table 3: Question - Members of my family used to read to me.

\begin{tabular}{lrrrrr}
\hline & $\begin{array}{r}\text { Strongly } \\
\text { agree }\end{array}$ & Agree & Uncertain & Disagree & $\begin{array}{r}\text { Strongly } \\
\text { disagree }\end{array}$ \\
\hline High Risk & $6 \%$ & $9 \%$ & $5 \%$ & $30 \%$ & $50 \%$ \\
Low Risk & $45 \%$ & $30 \%$ & $2 \%$ & $17 \%$ & $6 \%$ \\
\hline
\end{tabular}

reading experiences, which shows that these students have been inculcated into school literacy even before start of school. These students are mainly English and Afrikaans HL speakers. Majority of the students in the High Risk group (63\% and $80 \%$ ) disagreed with the statement, which is indicative of poor reading experience. Since these students were in the High Risk group, this indicates that poor reading experience is related to low reading literacy levels.

Reading experience proved to be statistically significant in relation to literacy groups: $F(4)=4.92, p=0.0006$. The significant $p$-value was 0.05 . Therefore any result below this figure was statistically significant. As the $p$-value for the relationship between reading experience and literacy level was 0.0006 , which is well below the significant 0.05 , the relationship was therefore very strong or robust. This shows that the relationship between the students' experiences with reading and their reading literacy levels is a very strong and robust one. The responses of the High Risk students were negative for reading experience compared to the Low Risk students. The results confirm the effect of previous reading experience on students' current reading literacy levels. In other words, students whose past reading experience was poor demonstrated low academic reading literacy level. This is shown in their low academic reading literacy. On the other hand, students who had rich past reading experience are less at risk, given their reading literacy level, and are more likely to succeed at university in comparison to the High Risk students.

In relation to language groups and reading experience, the ANOVA test showed significant differences: $F(3)=28.41, p<0.0001$. ISAL students indicated the most negative reading experience. English and Afrikaans HL students had 
positive reading experiences, though English HL speakers, who were mostly of negligible risk, were more positive. Since the $p<0.0001$ for this factor (less than 0.05) for the relationship between language groups and reading experience, a strong relationship can be said to exist between the two, and is shown in ISAL students having low reading literacy levels and English and Afrikaans students having better reading literacy levels.

\subsection{Literacy interactions}

Statements on social literacy also showed a distinction between the High Risk group mainly ISAL HL speakers and English/Afrikaans HL speakers. In other words indication of low literacy interactions was given by students in the High Risk group and indication of frequent literacy interactions was given by the Low Risk group. These responses show that students who have had poor social literacy interactions also had low literacy levels. Similarly, students who had experience rich social literacy interactions had high reading literacy levels. These results are also reflected in the language groups.

Majority of the ISAL students indicated minimal or non-existent literacy interactions whereas the majority of English and Afrikaans HL students were positive. This shows that the English and Afrikaans HL discuss texts with their family members, but very few of the ISAL students engage in this activity. The percentages of students' responses for two of the statements on literacy interactions, viz: "My friends and I discuss books that we read" and "My siblings read a lot" are given in Tables 4 and 5, respectively.

Table 4: Question - My friends and I discuss books that we read.

\begin{tabular}{lrrrrr}
\hline $\begin{array}{l}\text { Literacy group (predominant } \\
\text { language group) }\end{array}$ & $\begin{array}{r}\text { Strongly } \\
\text { agree }\end{array}$ & Agree & Uncertain & Disagree & $\begin{array}{r}\text { Strongly } \\
\text { disagree }\end{array}$ \\
\hline High Risk (predominantly ISAL) & $7 \%$ & $10 \%$ & $20 \%$ & $20 \%$ & $43 \%$ \\
Low Risk (predominantly English & $40 \%$ & $30 \%$ & $5 \%$ & $15 \%$ & $10 \%$ \\
$\quad$ and Afrikaans) & & & & \\
\hline
\end{tabular}

Table 5: Question - My siblings read a lot.

\begin{tabular}{lrrrrr}
\hline & $\begin{array}{r}\text { Strongly } \\
\text { agree }\end{array}$ & Agree & Uncertain & Disagree & $\begin{array}{r}\text { Strongly } \\
\text { disagree }\end{array}$ \\
\hline High Risk & $16 \%$ & $9 \%$ & $9 \%$ & $37 \%$ & $29 \%$ \\
Low Risk & $38 \%$ & $30 \%$ & $11 \%$ & $11 \%$ & $10 \%$ \\
\hline
\end{tabular}




\subsection{Reading habits}

The analyses showed that students' reading habits corresponded with their language groups and reading literacy levels. The majority of students who do not read much are in the High Risk group and are ISAL HL speakers. On the other hand, the English and Afrikaans HL speakers, the majority of whom are in the Low Risk group, read relatively more frequently than their peers in the High Risk group. The percentages of students' responses for two of the statements on reading habits, viz "I read one novel each month during school holidays" and "I often read novels”, are given in Tables 6 and 7, respectively.

Table 6: Question - I read one novel each month during school holidays.

\begin{tabular}{lrccrr}
\hline $\begin{array}{l}\text { Literacy group (predominant } \\
\text { language group) }\end{array}$ & $\begin{array}{r}\text { Strongly } \\
\text { agree }\end{array}$ & Agree & Uncertain & Disagree & $\begin{array}{r}\text { Strongly } \\
\text { disagree }\end{array}$ \\
\hline High Risk (predominantly ISAL) & $3 \%$ & $10 \%$ & $18 \%$ & $20 \%$ & $49 \%$ \\
Low Risk (predominantly English & $38 \%$ & $28 \%$ & $14 \%$ & $13 \%$ & $7 \%$ \\
$\quad$ and Afrikaans) & & & & & \\
\hline
\end{tabular}

Table 7: Question - I often read novels.

\begin{tabular}{lrrrrr}
\hline & $\begin{array}{r}\text { Strongly } \\
\text { agree }\end{array}$ & Agree & Uncertain & Disagree & $\begin{array}{r}\text { Strongly } \\
\text { disagree }\end{array}$ \\
\hline High Risk & $5 \%$ & $13 \%$ & $25 \%$ & $21 \%$ & $36 \%$ \\
Low Risk & $34 \%$ & $30 \%$ & $16 \%$ & $11 \%$ & $9 \%$ \\
\hline
\end{tabular}

The percentages given in Tables 6 and 7 show that whereas the High Risk students tend to disagree with the statements on reading habits and literacy interactions, the Low Risk students tend to agree. This is indicative of the literacy interactions and the reading behaviour of the students. The $p$-values from the ANOVA analysis are given in Table 8 to further indicate the distinction in students' social literacy, language groups and reading literacy levels.

Table 8: $P$-values for the relationships between reading literacy level, home/first language and the social factors (reading experience, literacy interactions and reading habits).

\begin{tabular}{|c|c|c|c|}
\hline \multirow[t]{2}{*}{ Variables } & \multicolumn{3}{|r|}{ Social factors } \\
\hline & Reading experience & Social literacy & Reading habits \\
\hline Literacy level & 0.0006 & & \\
\hline Home language & $<0.0001$ & 0.0067 & 0.0062 \\
\hline
\end{tabular}


The results show a robust relationship between social literacy and language groups, which was statistically significant at $F(3)=4.08, p=0.006$. Given the fact that the $p$-value of 0.006 is less than 0.05 the relationship between students' literacy interactions and language groups is statistically significant. In other words literacy interaction and language groups have a strong relationship that is evident statistically. The fact that language groups corresponded with literacy interactions for this cohort of students (e.g. ISAL HL students predominantly in High Risk group) indicates that indirectly, a relationship exists between social literacy and academic reading literacy. In other words social literacy interactions have a direct relationship with students' language groups and an indirect relationship with academic reading literacy levels. Students who have had minimal literacy interactions were mostly ISAL students and those who have had frequent literacy interactions were mostly English and Afrikaans HL speakers. Students' level of social literacy interactions therefore indicated their language groups directly, and indirectly determined their reading literacy levels. Also, given that certain language groups are predominant in a specific risk group, there is an indirect relationship between language groups and literacy levels.

Where the significant $p$-value was 0.05 , the relationship between reading experience and literacy level was 0.0006 . This shows that students' reading experience and their literacy levels are highly related as the $p$-value of 0.0006 is significantly less than 0.05 . In other words, for this cohort of students, a student who was identified as being at risk and therefore has low literacy levels would most probably have had a poor reading experience.

Similarly the $p$-value for the relationship between language groups and reading experience was 0.0001 . The fact that this $p$-value is significantly lower than 0.05 shows that a close relationship exists between language groups and literacy levels. In other words a student in a particular language group would have responded negatively or positively to reading experience. For example, an ISAL student in the High Risk group would possibly have had a poor reading experience, whereas an Afrikaans or English student in the Low Risk group would have responded positively to reading experience.

In relation to reading experience and literacy interactions, ISAL HL students were the most negative. This indicates that most of the ISAL HL students in this study had poor reading experience at home and at school and low literacy interactions. This confirms the link between social factors and language groups in South Africa (Currin and Pretorius 2010; Pretorius 2000; Taylor and Yu 2009). Students who reported poor reading experience also reported low literacy interactions, while those who indicated rich reading experiences also indicated high literacy interactions. 
Students' language groups and social literacy (i.e. reading experience, literacy interactions and reading habits) corresponded with their reading literacy. This means that for this cohort of first-year students, those who have had low social literacy at home and in their previous schooling, also have low reading literacy levels. The majority of these students are ISAL HL speakers. The reverse is also true for students who have had rich social literacy at home and at school, the majority of whom are English and Afrikaans HL speakers.

Students' reading habit seems to result from their reading experiences and literacy interactions. Positive reading experiences and rich literacy interactions seem to lead to positive reading habits and learning behaviours.

Significant results, indicating a relationship between reading habits on the one hand, and language groups and literacy levels on the other, showed that ISAL HL speakers in the negligible risk group had the best reading habits among this cohort of students. This group of ISAL HL speakers, as mentioned above, displays different reading characteristics from ISAL HL speakers in the other literacy groups, probably because of their higher SES family background, and also because of the school they attended. As mentioned earlier, the open access in education after 1994 saw a migration of ISAL HL speakers (predominantly from middle-class families) to historically white schools.

In sum, ANOVA test showed that social factors corresponded with reading literacy, sometimes in a robust relationship. However, factors that did not show a direct relationship with reading literacy showed a relationship with students' first language, indicating an indirect relationship with reading literacy levels. Thus it can be concluded that there is a direct relationship between students' reading literacy and their reading experience, and an indirect relationship between their reading literacy levels and their social literacy, as shown in Table 6.

\section{Discussion}

The results of the study show that the majority of the ISAL HL students were negative in their responses to reading experience, while almost all the Afrikaans and English HL students indicated positive reading experiences. This shows that the students were disproportionately exposed to different reading experiences, which may reveal inequalities in their reading performance at tertiary level/ institutions and market opportunities.

The results also showed differences in students' social literacy interactions. Whereas the ISAL HL students responded negatively to social literacy interactions (i.e. do not discuss texts with family and friends, and family and friends do not read 
much) the Afrikaans and English HL students provided more positive responses to questions on social literacy interactions. The underlying assumption could be sociocultural. The ISAL HL students, many of whom are from low SES families (Boakye and Southey 2008), may have literacy interactions different from the formal academic context, the English and Afrikaans HL speakers, many of whom are from middle and high SES families, may have literacy interactions that are compatible to the academic context. This difference may provide the latter group a head start in school, as argued by Taylor and Yu (2009). Unfortunately, the education system perpetuates this division, as many of the ISAL students attend historically disadvantaged schools (Taylor and Yu 2009; Pretorius 2007). The literacy gap between the two groups then becomes more distinct at the tertiary level where AL demands are higher and more complex. At the tertiary level, reading is more demanding and requires students to apply higher level reading skills and abilities (for example, inferencing, critical analysis and synthesising [Boughey 2009]). As a result, students who have had poor social literacy operate at tertiary level with poor reading strategies, poor comprehension skills, a lack of critical reading skills, poor inferencing and analytical skills and little if any love for reading. They find reading burdensome and generally read at frustration levels (Pretorius 2000). Unfortunately for these students school literacy is mainly taught from a cognitiveoriented perspective, focussing on cognitive skills, with little if any regard to the social dimension of reading literacy and the different literacies that students bring.

Furthermore the results also show that ISAL students do have negative reading habits. In other words most of them do very little reading or do not read for pleasure. This may be a culmination of the poor reading experience and low social literacy interactions. The advantages of reading for pleasure, such as enabling appropriate use of reading strategies, and increasing comprehension and speed (Grabe and Stoller 2002), indicate that without students engaging in this activity, they would probably arrive at tertiary institutions lacking these skills. The assumption for students' lack of pleasure reading could again be attributed to socio-cultural practices among others. Communities that do not elevate individual reading but dwell on collective oral discussions as found in Niven's (2005) study of ISAL students could influence this non-reading culture. Different literacy practices may influence learners' reading habits. For example, some language communities view reading as solely for utilitarian purposes (Carstens 2004: 19). Reading for pleasure is not encouraged. In other language communities, an individual's frequent immersion in a book may be frowned upon and said to encourage laziness (Pretorius 2010, personal communication). There is therefore little interaction with texts at home.

These factors place the ISAL HL speakers at a disadvantage. First of all most of the English and Afrikaans HL speakers are from print-rich homes and have had 
early literacy interactions that are compatible with schooled literacy. Secondly, English and many Afrikaans HL speakers have had instruction in their HL from the foundation level, giving them a firm grounding in schooled literacy practices.

Taylor and $\mathrm{Yu}$ (2009) explain that the lowest scores of South Africans in the PIRLS test were due to the performance of ISAL HL speakers who are in the poorly functioning schools. Their analysis showed that when the two systems are separated the white schools showed a much better reading proficiency than the historically disadvantaged schools which have a concentration of learners from low SES, and are ISAL HL speakers.

In addition, as a number of ISAL HL speakers are from low SES families (Taylor and $\mathrm{Yu}$ 2009), their literacy interactions with texts at home before formal schooling and during formal schooling is minimal as shown in the study. Among other reasons there is limited written material in the indigenous languages, and printpoor home environment may be due to the educational and financial status of parents. Moreover, students from the ISAL language community who mostly belong to low SES families may experience literacy interactions differently from the literacy practices of the English and Afrikaans language groups and that of the school.

The research question for the study was to investigate whether there is a relationship between social factors and students' reading literacy levels. The results of the study showed that a robust relationship exists between social factors and reading literacy levels. In other words students who responded negatively on social literacy were mostly in the High Risk group, whereas those who responded positively were mainly in the Low Risk. The relationship points to the fact that students' social literacy and reading background may influence their literacy levels, including reading proficiency, at the tertiary level.

The consistent negative response of ISAL students to reading experience is indicative of their minimal social literacy and past reading experience that they have had. Their responses may also be attributed to their different ways of knowing, which may be culturally distant from what schools expect of them. As explained earlier these students attend historically disadvantaged and currently poorly functioning schools, and were exposed to fewer resources due to socio-political conditions that deprived them of equal opportunities. Yet after 20 years of democracy the influence of the bimodal system still exists. For such students it is even more crucial to align instruction to their socio-cultural frames as advocated by Niven (2005) and Napier and Makura (2013).

An important finding that emerged from this survey is that students' HL was statistically significant for all three social factors. It indicates that the students' HL corresponded with their past reading experience, their social literacy and their reading habits. The assumption here is that it is not the HL per se that influences students' reading literacy levels, but there seems to be a combination of factors 
that include SES, educational background including school attended, past reading experience, social literacy, reading habits and other socio-cultural factors associated with certain HL groups that lead to poor reading proficiency (Gee 2008; Heath 1983; Street 2003; Taylor and Yu 2009). Given the low literacy levels of the majority of ISAL students, as shown by the study, they would need instruction that adequately and directly addresses their social and affective needs, while developing their cognitive reading abilities (Grabe and Stoller 2002; Guthrie and Wigfield 2000; Verhoeven and Snow 2001). According to Guthrie and Wigfield (2000), appropriate reading instruction can provide students with learning opportunities that are equivalent to several years of education.

As discussed above, social literacy corresponded with overall reading behaviour and literacy levels. Students who have had social literacy compatible to schooled literacy (i.e. English, Afrikaans and middle-class ISAL speakers) tend to be proficient readers, at low risk of failure academically. Those with social literacy practices that are different from the school literacy practices (i.e. majority of ISAL) converge in poorly resourced schools, and end up as less proficient readers and at high risk of failure academically without intensive intervention. Given the high level reading demands at tertiary level, the gap widens in favour of those who have comparable social literacy to the school and attend well-resourced schools due to their SES. One way of bridging the gap is to make reading instruction socially relevant, so that the ways of knowing of the ISAL group can be harnessed.

One way of making reading literacy instruction socially relevant is for educators to be sensitive to the socio-political environment and recognise the broader social, political, historical and economic conditions that affect the lives of learners and acknowledge that these conditions also affect classroom aims and activities (Napier and Makura 2013). Kumaradivelu (2003) argues that the experiences that learners bring to the classroom are shaped not only by the learning episodes they have encountered in the past, but also by the broader community and sociopolitical environment in which they grew up. These experiences have the potential to affect classroom activities such that learners' previous educational backgrounds, home environment, the community and the larger society exert great influence on classroom participation and management. As a result, educators cannot afford to ignore these socio-political and socio-cultural realities that influence identity formation in the classroom (Gee 2008). Thus, according to Kumaravadivelu (2003), educators cannot afford to separate the linguistics and literacy needs of learners from their social needs. In practice, reading literacy instruction should be aimed at addressing social inequalities as well, by adopting strategies that empower all language groups, in particular, disadvantaged ISAL HL students.

In addition, as Kumaravadivelu (2003) suggests in second language teaching, educators should strive to raise the cultural consciousness of students. In other 
words, they need to treat learners as cultural informants in order to encourage them to engage in the process of classroom participation that recognises and elevates their power and knowledge. Using the learners' home culture (in this context ISAL HL students) to inform classroom activities facilitates better comprehension, and enables students to become motivated and empowered. Niven (2005: 787), discussing the conflict of frames between lecturers and students, states that "there needs to be a rapprochement of frames" between lecturers and students, and that lecturers should consider the diverse literacies that students bring and develop a more authentically indigenous South African academic culture. This approach to reading literacy instruction if adopted will assist, in particular, ISAL HL students who have worked hard to gain university entrance but come from historically disadvantaged and poorly functioning schools.

Students who have been deprived socially and educationally (e.g. no access to libraries, poor resources, minimal interaction with texts due to SES and sociocultural conditions) may reflect these deprivations in the classroom. As Niven argues, students who have operated on an oral tradition as a form of literacy cannot be expected to engage with texts in the same manner as those who have interacted with texts in the home right from infancy. In addition students whose social literacy is different from the school find the academic demands daunting and overwhelming. As Niven (2005) states, they become "anxious, withdrawn and passive". If positive strategies such as social relevance and cultural consciousness are not adopted to harness their diverse literacies in socialising them into AL practices, they may face enormous academic challenges and consistent failure. Thus the academic gap between ISAL students and their English and Afrikaans counterparts becomes even wider.

Social literacy may determine reading literacy levels, and negatively so, for certain language groups. The issue lies with different socio-cultural approaches to literacy and varying socio-political and educational conditions. As a result, redress in the academic environment should go beyond sole cognitive support, to entail support that is socially relevant in order to socialise ISAL students into academic practices in ways that they can identify with. That kind of support will help to equalise the playing field at the tertiary level, otherwise the education

system will continue to perpetuate the division and distinction between the different language groups.

\section{Conclusion}

In this article, I presented the argument that the social dimension of reading, in particular social literacy, has a profound influence on students' reading literacy. As 
such, ISAL students who have had minimal social interactions with texts (MTs not developed due to a long history of colonialism and apartheid) and whose social literacy practices may be different from the school's evidence lower reading literacy levels, whereas the English and Afrikaans HL speakers, together with few middleclass ISAL speakers who have had rich social interactions with texts in English or Afrikaans, and observe literacy practices similar to the school, have relatively higher reading proficiency. As a result of the dynamics between social literacy, SES and education in South Africa, a wide gap exists between the different language groups, specifically between a majority of ISAL students, on the one hand, and English and Afrikaans students on the other. This perpetuates racial inequality in higher education and overall success in life. I have suggested that one of the ways of narrowing the gap between the two groups is to make reading instruction socially relevant for the ISAL students in particular, and to raise their cultural consciousness, in other words, to introduce a pedagogy that validates the cultural identities of students who were disproportionally exposed to fewer reading materials both at home and at school.

The study did not directly elicit the SES of students. This was inferred from the responses to reading experience and social literacy. It will be important for subsequent studies to directly elicit responses on students' SES and particular schools attended in order to make strong claims on the relationship between SES, school system, social literacy, language groups and literacy levels of students.

\section{Appendix}

\section{Questionnaire on social literacy \\ For office use}

Respondent number

Please tick (using a X) the number that best reflects your opinion accurately

\begin{tabular}{|c|c|c|c|c|c|c|}
\hline $\begin{array}{l}\text { Past experiences } \\
\text { with reading }\end{array}$ & $\begin{array}{r}\text { Strongly } \\
\text { agree }\end{array}$ & Agree & Uncertain & Disagree & $\begin{array}{l}\text { Strongly } \\
\text { disagree }\end{array}$ & \\
\hline $\begin{array}{l}\text { 1. When I was a child I was often } \\
\text { taken to the library }\end{array}$ & 1 & & 3 & 4 & 5 & V1 \\
\hline $\begin{array}{l}\text { 2. Members of my family used to } \\
\text { read to me }\end{array}$ & 1 & 2 & 3 & 4 & 5 & V2 \\
\hline $\begin{array}{l}\text { 3. There have always been books in } \\
\text { my family's home }\end{array}$ & 1 & 2 & 3 & 4 & 5 & V3 \\
\hline
\end{tabular}


(Continued)

\begin{tabular}{lrrrrrr}
\hline $\begin{array}{l}\text { Past experiences } \\
\text { with reading }\end{array}$ & $\begin{array}{c}\text { Strongly } \\
\text { agree }\end{array}$ & Agree & Uncertain & Disagree & $\begin{array}{c}\text { Strongly } \\
\text { disagree }\end{array}$ & \\
\hline $\begin{array}{l}\text { 4. Attention was given to } \\
\text { developing reading skills in my }\end{array}$ & 1 & 2 & 3 & 4 & 5 & V4 \\
$\begin{array}{l}\text { high school } \\
\text { 5. There was a library in my primary } \\
\text { school }\end{array}$ & 1 & 2 & 3 & 4 & 5 & V5 \\
$\begin{array}{l}\text { 6. There are } 20 \text { or more books in my } \\
\text { home }\end{array}$ & 1 & 2 & 3 & 4 & 5 & V6
\end{tabular}

\section{Literacy interactions}

7. My siblings read a lot

8. My parents read a lot

9. My friends like reading so they read a lot

10. My friends and I discuss books that we read

11. I know people who read all kinds of texts

\section{Reading habits}

12. I read one novel each week/ month during holidays

13. I read one novel each week/

$\begin{array}{ll}1 & 2 \\ 1 & 2 \\ 1 & 2\end{array}$

\section{3}

$\begin{array}{ll}5 & \text { V7 }\end{array}$

3

3

$5 \quad$ V8

5 V9

month during school term

14. I often read

i. newspapers

ii. magazines

iii. novels

iv. academic books

v. any other (e.g. motivational, plays, etc)

15. I read books/magazines/ newspapers in my mother-tongue

16. Newspapers are bought daily/ weekly in my home

\section{Personal information}

17. Gender

19. Literacy level

20. Mother tongue

1

12

12

12

3

4

$5 \quad$ V13

$5 \quad \mathrm{~V} 10$

$5 \quad$ V11

3

4

5

V12

$\begin{array}{llllll}1 & 2 & 3 & 4 & 5 & \mathrm{~V} 14 \mathrm{i} \\ 1 & 2 & 3 & 4 & 5 & \mathrm{~V} 14 \mathrm{ii} \\ 1 & 2 & 3 & 4 & 5 & \mathrm{~V} 14 \mathrm{iii} \\ 1 & 2 & 3 & 4 & 5 & \mathrm{~V} 14 \mathrm{iv} \\ 1 & 2 & 3 & 4 & 5 & \mathrm{~V} 14 \mathrm{v} \\ 1 & 2 & 3 & 4 & 5 & \mathrm{~V} 15 \\ 1 & 2 & 3 & 4 & 5 & \mathrm{~V} 16\end{array}$

$\begin{array}{rrrrrr}F & & M & & & \text { V67 } \\ 1 & 2 & 3 & 4 & 5 & \text { V68 } \\ \text { Eng } & \text { Afr } & \text { SA } & \text { Other } & \text { Other } & \text { V69 } \\ & & \text { African } & \text { African } & & \end{array}$

Student number 


\section{References}

Alderson, Charles J. 2000. Assessing reading. Cambridge: Cambridge University Press.

Barton, David \& Mary Hamilton. 1998. Local literacies: Reading and writing in one community. London: Routledge.

Boakye, Naomi \& Lynne Southey. 2008. Investigating students' motivations and attitudes towards reading. Journal for Language Teaching 42(2). 7-24.

Boughey, Chrissie. 2009. South Africa: University students can't read? University World News online 0090. www.universityworldnews.com/article.php?story $=20090827173247724$ (accessed August 2010).

Bus, Adriana. 2001. Parent-child book reading through the lens of attachment theory. In Ludo Verhoeven \& Catherine Snow (eds.), Literacy and motivation: Reading engagement in individuals and groups, 39-53. Mahwah, NJ: Lawrence Erlbaum Associates.

Carstens, Adelia. 2004. HIV/AIDS, literacy and health communication. A study on the comprehension of visual symbolism in educational documents produced for people with limited reading skills. Image and Text 11. 11-22.

Currin, Sally \& Elizabeth J. Pretorius. 2010. The culture of the sharp pencil: Can a literacy intervention lever school change? Reading and Writing 1(1). 23-46.

De Klerk, Vivian. 2002. Language issues in our schools: Whose voice counts? Perspectives in Education 20(1). 1-14.

Elley, Warwick B. 1996. Lifting literacy levels in developing countries. In V. Greany (ed.), Promoting reading in developing countries, 39-54. Newark, DE: International Reading Association.

Fleisch, Brahm. 2008. Primary education in crisis: Why South African schoolchildren underachieve in reading and mathematics. Cape Town: Juta.

Freebody, Peter, Christine Ludwig \& Stephanie Gunn. 1995. Everyday literacy practices in and out of schools in low socioeconomic urban communities. Brisbane: Centre for Literacy Education Research, Griffith University.

Gee, James Paul. 1991. Social literacies: Ideology in discourses. New York: Routledge.

Gee, James Paul. 2008. Social linguistics and literacies: Ideology in discourses. London: Falmer Press.

Goodman, Ken. 1976. Manifesto for a reading revolution. In F. V. Gollasch (ed.), Language and literacy: The selected writings of Kenneth S. Goodman, 231-241. London: Routledge \& Kegan Paul.

Grabe, Will \& Fredericka Stoller. 2002. Teaching and researching reading. London: Pearson Education.

Greaney, Vincent. 1996. Reading in developing countries: Problems and issues. In V. Greany (ed.) Promoting reading in developing countries, 5-37. Washington, DC: International Reading Association.

Guthrie, John T. \& Alan Wigfield. 2000. Engagement and motivation in reading. In M. L. Karmil, P. B. Mosenthal, P. D. Pearson \& R. Barr (eds.), The handbook of reading research, vol. III, 403-420. Mahwah, N): Lawrence Erlbaum Associates.

Heath, Shirley Brice. 1983. Ways with words: Language, life and work in communities and classrooms. Cambridge: Cambridge University Press.

Heath, Shirley Brice. 2001. What no bedtime story means: Narrative skills at home and school. In A. Duranti (ed.), Linguistic anthropology: A reader, 318-342. Oxford: Blackwell. 
Jansen, Leanne. 2013. African language mandatory: Primary schools first in bid to foster social cohesion. The Star Tuesday May 21. 7.

Kumaravadivelu, B. 2003. Beyond methods: Macrostrategies for language teaching. New Haven: Yale University Press.

Makalela, Leketi. 2012. Development of L1 and L2 reading literacy among fifth graders: Implications for research-based teacher education. In R. Osman \& H. Venkat (eds.), Research led teacher education, 127-144. Cape Town: Pearson.

Napier, Astrid. \& Alfred H. Makura. 2013. Students' and staff perceptions of the efficacy of English language literacy support programmes for students at a previously disadvantaged higher education institution in South Africa. International Journal of Educational Science 5(1). 1-10.

Niven, Pillay M. 2005. Exploring first year students' and their lecturers' constructions of what it means to read in a humanities discipline: A conflict of frames? South African Journal of Higher Education 4(19). 777-789.

Pretorius, Elizabeth J. 2000. Inference generation in the reading of expository texts by university students. Pretoria: University of South Africa unpublished doctoral thesis.

Pretorius, Elizabeth J. 2007. Looking into the seeds of time: Developing academic literacy in high poverty schools. Ensovoort 11(2). 105-125.

Pretorius, Elizabeth J. 2008. What happens to literacy in (print) poor environments? Reading in African languages and school language policies. In Proceedings of CentRePol/IFAs workshop, University of Pretoria, 29 March 2007, 60-88. Johannesburg: Institut Francais d'Afrique du Sud.

Prinsloo, Mastin. 2005. Studying literacy as situated social practice: The application and development of a research orientation for purposes of addressing educational and social issues in South African contexts. Cape Town: University of Cape Town unpublished PhD thesis.

Serpell, Robert. 2001. Literacy empowerment in developing societies. In L. Verhoeven \& C. E. Snow (eds.), Literacy and motivation, 222-250. London: Lawrence Erlbaum.

Street, Brian. 1984. Literacy in theory and practice. Cambridge: Cambridge University Press.

Street, Brian. 1997. The implications of the 'New Literacy Studies' for literacy education. English in Education 31(3). 45-59.

Street, Brian. 2003. What's "new" in New Literacy Studies? Critical approaches to literacy in theory and practice. Current Issues in Comparative Education 5. 1-14.

Street, Brian (ed.). 2001. Literacy and development. London: Routledge.

Taylor, Stephen \& Derek Yu. 2009. Socio-economic status and educational achievement: Does education provide a stepping stone out of poverty in South Africa? Transformation Audit 66-75. Online http://www.ijr.org.za/publications/pdfs/IJR_TA_Prelims.pdf (accessed September 2013).

Van der Berg, Servaas. 2008. How effective are poor schools? Poverty and educational outcomes in South Africa. Studies in Educational Evaluation 34(3). 145-154.

Verhoeven, Ludo \& Catherine E. Snow. 2001. Literacy and motivation. London: Lawrence Erlbaum Associates.

Weideman, Albert. 2011. Academic literacy tests: Design, development, piloting and refinement. Journal of Language Teaching 45(2). 100-113. 